\title{
Design and Implementation of a Vacuum Forming Machine
}

\author{
Botond-Antal BIRTON, ${ }^{1}$ Attila GERGELY ${ }^{2}$ \\ ${ }^{1}$ University of Sapientia EMTE, Faculty of Technical and Human Sciences, Târgu Mureș, Mechanical \\ engineering profile, IVth grade, Târgu Mureș, Romania, birtonboty4@gmail.com \\ ${ }^{2}$ University of Sapientia EMTE, Faculty of Technical and Human Sciences, Târgu Mureș, Department of \\ Mechanical engineering, Târgu Mureș, Romania, agergely@ms.sapientia.ro
}

\begin{abstract}
The purpose of this work is to present the design of a laboratory scale vacuum forming machine, which can be used for the processing of thermoplastic sheets. The designed machine can process an A4 format plastic sheet. An important consideration in the design process was to follow a cost-effective approach. The vacuum forming instrument is made for educational purposes in the framework of a final project for the Polymer Technology Laboratory of the Department of Mechanical Engineering of the Sapientia EMTE University in Târgu Mureș. The structure and the operation of the machine is similar to that found in the industry. However, the cost of production is significantly lower. The main components of the machine include the frame, heater, vacuum pump and the clamping device.
\end{abstract}

Keywords: vacuum forming, thermoplastics, design, processing plastics.

\section{Introduction}

Vacuum formed plastic were first used as an appearance and marketing tool, when the technology was developed from molding, and vacuum casting technologies in the 1940s and 1950s. The first device, which was patented in 1950, was used to make screen covers, and then, using various methods and solutions, a final vacuum forming machine for plastic sheet was patented in 1964. All of the vacuum forming machines started from an old concept, according to which, in any molding or casting procedure, the excess trapped air was removed by applying a vacuum. Removing the trapped air from the casting tools has a very important role in all kinds of forming and casting technologies, because it can induce weak points in the workpiece, therefore its strength will no longer fit the design requirements and it can crack or break. To eliminate this problem a vacuum is applied so that any trapped or excess air can be removed, thereby ensuring a perfect and even mold filling [1].

The technology was further improved by fixing the plastic sheet to a frame, and then heating it before molding. As a result of the heating, the plastic sheet softens, enters a shapeable state, and can thus be formed more easily. The heat-assisted vacuum forming machine was patented on $\mathrm{Au}$ gust 27, 1968 [2].

Vacuum forming technology is one of the oldest and most common methods for thermoplastic processing. Nowadays, vacuum formed plastic products can be found almost everywhere. Examples of such products can be simple packaging, toy cars and their packaging, prototype, etc. [3].

As a simple definition, vacuum forming is a forming process in which a thermoplastic sheet with a given thickness is heated to a temperature at which it can be properly formed, and then stretched to a shape with a given geometry and size while applying a vacuum. With the help of the vacuum, the sheet perfectly aligns to the tool, and then, with the help of cooling, it permanently preserves its shape. Once the workpiece has cooled sufficiently and hardened, it is safely removed while paying attention not to damage its surface or change its shape. The workpiece is then subjected to post processing, where the excess material is removed $[4,5]$.

The most commonly used plastics for vacuum forming are the HIPS (high impact polystyrene), PVC (polyvinyl chloride), ABS (acrylonitrile butadiene styrene), PP (polypropylene), PC (polycarbonate) [5]. 


\section{Presentation of the vacuum forming machine}

\subsection{Operation and 3D model}

The 3D model of the vacuum forming machine is presented in Figures 1 and 2 The material that is used in the project is a $1 \mathrm{~mm}$ thick polycar-

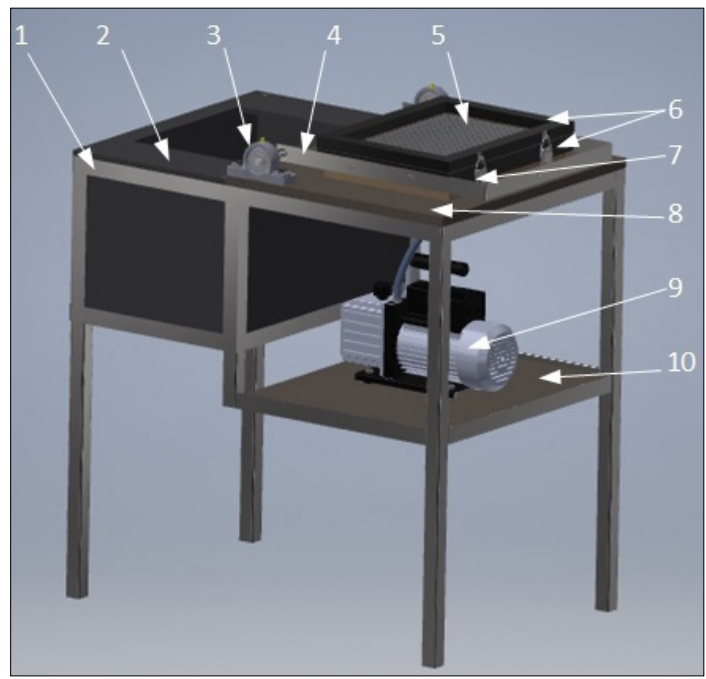

Figure 1.3D model of the designed vacuum forming machine.

1 - frame, 2 - heater box, 3 - bearing, 4 -frame for the sheet clamping mechanism, 5 - perforated metal sheet, 6 - plastic sheet clamping frames, 7 - clamp locks, 8 -vacuum box support plate, 9 - vacuum pump, 10 - vacuum pump support plate.

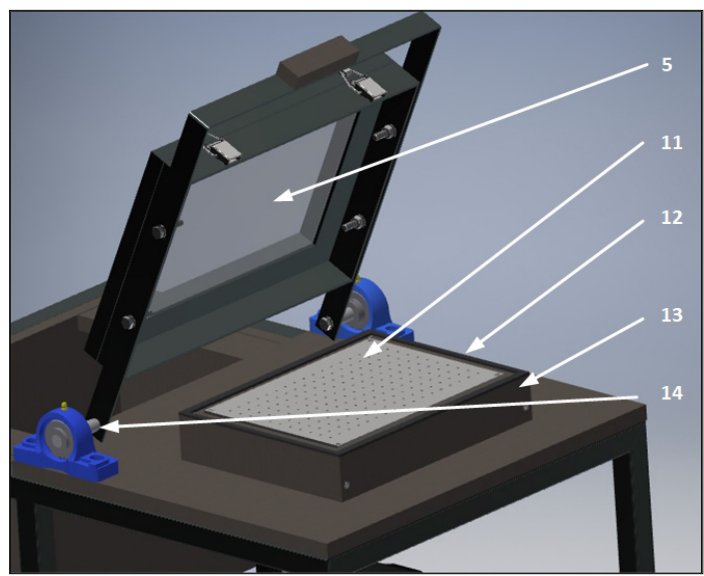

Figure 2.3D model of the designed vacuum forming machine in open state.

5 - perforated metal sheet, 11 - plastic sheet, 12 - rubber seal, 13 - vacuum box, 14 - shaft. bonate sheet. The operation of the device consists of the following steps. Firstly, the plastic sheet is inserted between the upper and the lower clamping frame (6), and is then fixed with the help of the clamp locks (7), thereby securing its position during the forming process. The machine has a rotating structure that simplifies and speeds up the process of moving the plastic sheet between the heater (2) and the forming unit. After placing the sheet, the second step is the heating process, which takes place on the left side of the device. The rotating frame (4) is tilted to the left side, and the heater is switched on. The heating continues until the thermoplastic polymer reaches a temperature at which it becomes sufficiently soft that it can be easily formed. This state of the polymer sheet can also be observed by eye, because it becomes transparent or, in case of a colored sheet, the color of the sheet becomes more vibrant. This step can be perfected with some experience or by measuring the heating time. One method to improve the accuracy of this process is the measuring of the sheet's temperature, but this solution is noted as an improvement, and not used in this design due to the cost-effective approach of the equipment. As a third step, after the plastic has been softened, the vacuum pump is turned on, and the clamping frames (6) with the rotating frame (4) are turned over to the right side of the machine. In this part there is a vacuum box (13), and on the top of the vacuum box there is a metal sheet (5), which has several holes where the effect of the vacuum prevails. The forming object is placed on this metal sheet (5). The thermoplastic polymer sheet is stretched onto the forming object, and then the trapped air between the two is removed by the vacuum pump, thereby the plastic sheet takes the shape of the given object.

\subsection{Structure}

\subsubsection{Frame}

The designed equipment is placed onto a frame which is shown in Figure 3. The frame structure is made out of $30 \times 30 \times 3 \mathrm{~mm}$ square profile, and L profile by welding. The frame has a size of $800 \times 550 \times 800 \mathrm{~mm}$, a $340 \times 540 \times 300 \mathrm{~mm}$ section on the left side for the heater, and a $440 \times 540 \times 390 \mathrm{~mm}$ section on the right side of the device for the vacuum pump.

\subsubsection{Heater unit}

A Zilan brand heater, with a power of $1200 \mathrm{~W}$ is used for the heating of the thermoplastic sheet 
that is going to be formed. The sheets need to be heated above their glass transition temperature (Tg), which depends on the type of plastic. In the case of $\mathrm{PC}, \mathrm{Tg}=+140^{\circ} \mathrm{C}$ [4]. Heaters used in the industrial machines are Quartz element heaters, or ceramic plate heaters. To reduce costs, an ordinary electric heater is used that contains three quartz heating elements, with a power of $400 \mathrm{~W}$ per element, and a total power of $1200 \mathrm{~W}$, as shown in Figure 4.

\subsubsection{Clamping unit}

The thermoplastic polymer sheet to be formed is placed between the lower and the upper frames (6), and clamped by the clamping locks (7). The lower clamping frame on which the plastic sheet is placed is made of four $30 \times 30 \times 3 \mathrm{~mm} \mathrm{~L}$ profiles, which are welded together to form the rectangular frame structure shown in Figure 5. The upper clamping frame is made out of four $20 \times 30 \times 3 \mathrm{~mm}$ square profiles, that are welded together to form the rectangular frame. The lower clamping frame (6) is fastened with 4 M8 screws to the metal frame (4), which can rotate by the no. 14 shafts shown in Figure 2. The rotatable metal frame (4) was prepared by forming a $30 \times 3 \mathrm{~mm}$ sheet into a U-shape. Two $\phi 15 \mathrm{~mm}$ diameter shafts were attached to the ends of the frame (4) by M8 screws. The shafts are mounted to bearings with UCP 202 bearing housings. Each bearing housing is fastened to the frame structure by 2 M8 screws.

\subsubsection{Vacuum pump}

A vacuum pump is used to suck out the trapped air between the no. 11 polymer sheet and the no. 5 metal sheet. The pump that is used is a Value V-i120SV pump, with a power of $\sim 184 \mathrm{~W}$, a flow rate of $51 \mathrm{~L} / \mathrm{min}$, an ultimate vacuum of $0.2 \mathrm{~Pa}$, which corresponds to $0.2 \times 10^{-6} \mathrm{bar}$. The pump is fitted with a manometer, as shown in Figure 6 which shows the actual vacuum [6].

The vacuum pump is connected to the no. 8 vacuum box support plate by FESTO piping, with an internal diameter of $8 \mathrm{~mm}$, which is fitted with quick connectors at both ends.

\subsubsection{Vacuum box}

The vacuum box (13) provides the feasibility of the vacuum between the no. 5 metal plate shown in Figure 1 and the plastic sheet. The box has a rectangular shape, it is made out of wood, and has the dimensions of $350 \times 370 \times 51 \mathrm{~mm}$. We fastened the vacuumbox to its no. 8 support plate by wood

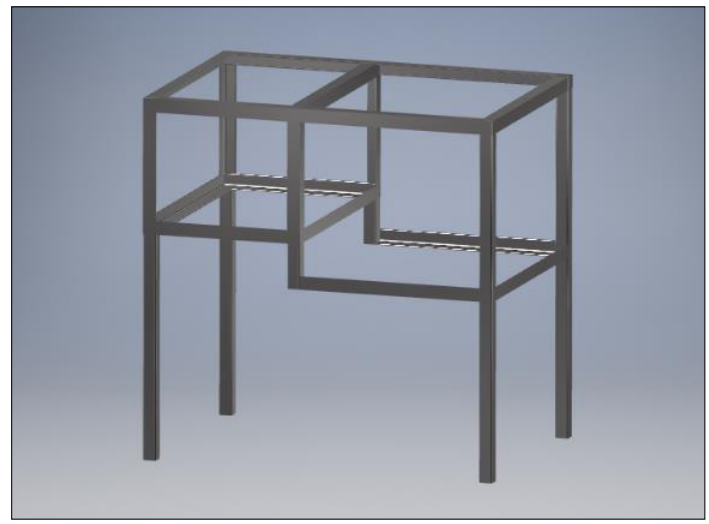

Figure 3. The frame of the device.

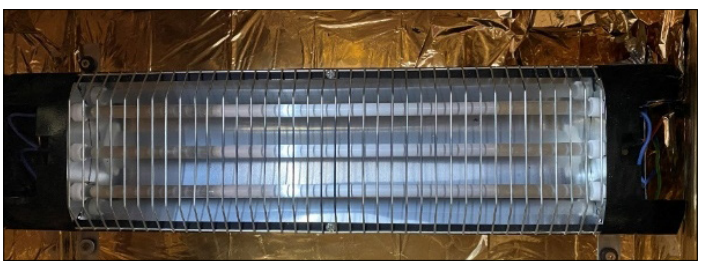

Figure 4. Heater unit.

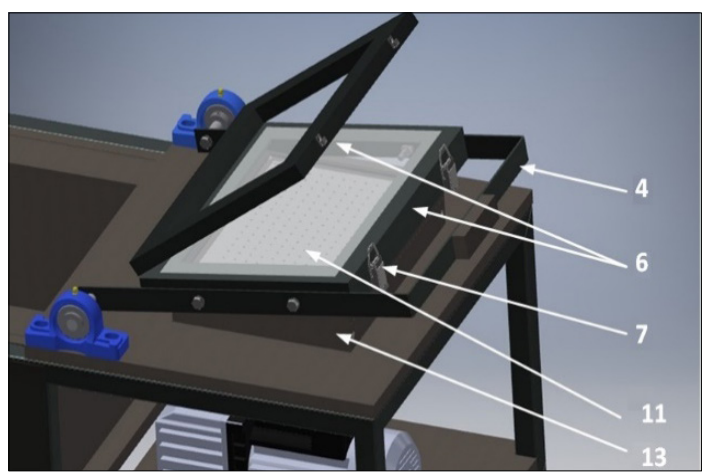

Figure 5. Clamping device and the rotating frame. 4 -rotating frame, 6 - upper and lower clamping frame, 7 - clamp locks, 11 - plastic sheet, 13 - vacuum box.

screws, and the seal between the box and the support plate was provided with silicone.

A hole with a diameter of $\phi 14 \mathrm{~mm}$ was drilled in the no. 8 support plate, to which a $1 / 2$ " quick connector (15) was attached, and FESTO piping was connected to this.

The no. 5 metal sheet shown in Figure 2 was fastened to the vacuum box by wood screws.

The no. 12 rubber seal provides the seal between the lower clamping frame (6) and the plastic sheet (11) in order to make the vacuum process as efficient as possible. 


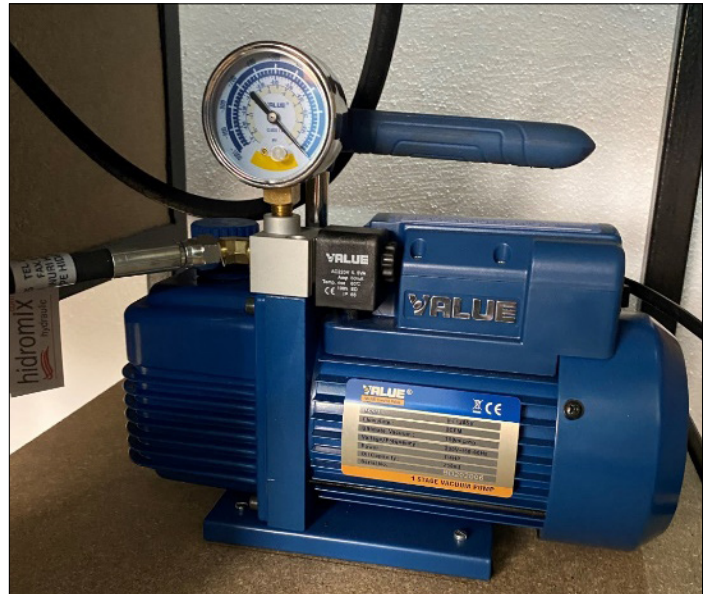

Figure 6. Vacuum pump. [6]

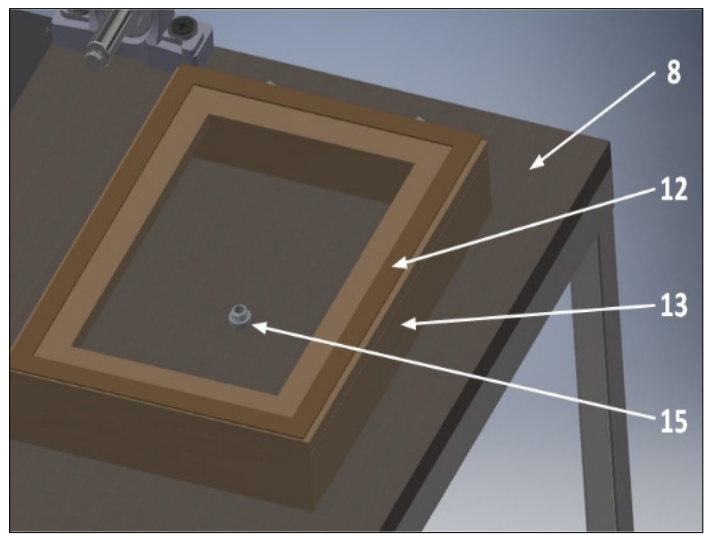

Figure 7. The model of the vacuum box.

8 - vacuum box support plate, 12 - rubber seal, 13 - vacuum box, 15 - vacuum hose connector.

Figure 8 shows the product that was made with the designed vacuum forming machine. It can be seen in the figure, that the $1 \mathrm{~mm}$ thick PC sheet picked up the geometry of the forming unit.

\section{Conclusions}

Within the framework of this project we presented the structure and the design steps of a vacuum forming machine intended for educational purposes. The operation of the designed machine is similar to machines that are used in the industry, but the build is much cheaper. With the help of this equipment, students can learn the vacuum forming method more easily, and perform various laboratory exercises with it.

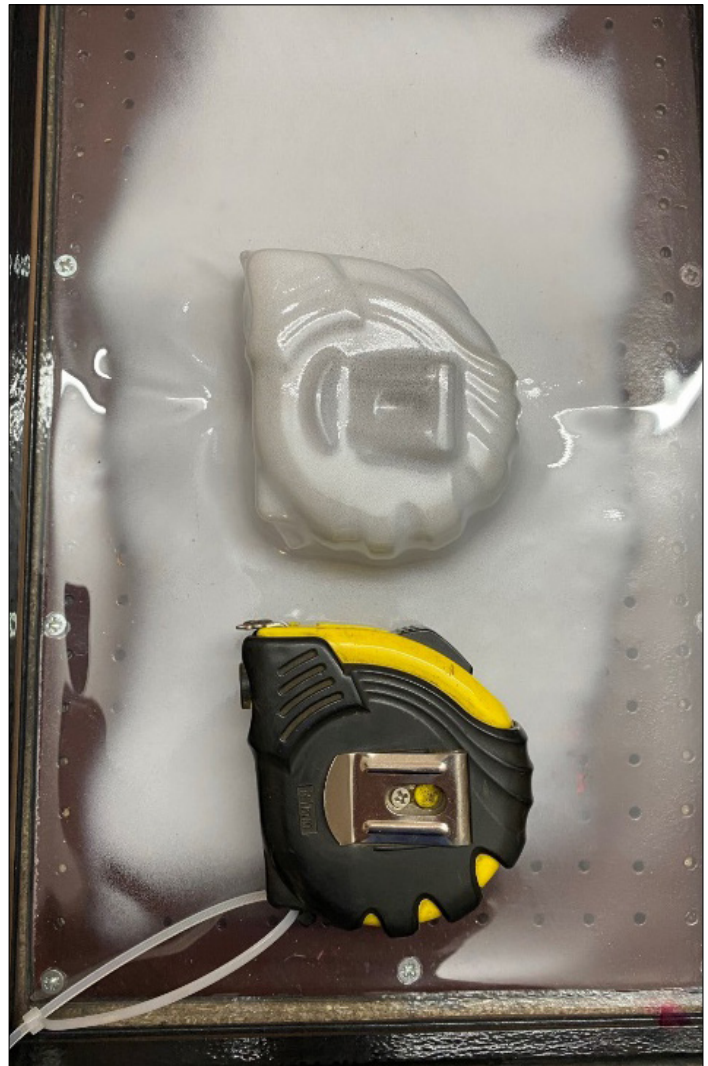

Figure 8. The piece made with the designed vacuum forming machine.

\section{References}

[1] Display developments UK: The history of vacuum forming. (accessed on: Febr. 3, 2021.)

https://www.displaydevelopments.co.uk/bespoke-manufacturing/the-history-of-vacuum-forming-ib-204.html

[2] Alesi J. Jr., Alesi J.: Vacuum forming apparatus, 1968. US3398434A

[3] Advancedtek: Vacuum forming guide. (accessed on: Febr. 3, 2021. )

http://www.advancedtek.com/wp-content/uploads/2018/12/Vacuum-Forming-Guide.pdf

[4] Czvikovszky T., Nagy P., Gaál J.: A polimertechnika alapjai. Mủegyetemi kiadó, Budapest, 2000. 54.

[5] C. W. Thomas: Thermoforming Design Guide. (accessed on: Febr. 3, 2021.)

https://www.cwthomas.com/wp-content/uploads/2016/12/Design-Guide.pdf

[6] Valuetool: Vacuum pump V-i120SV. (accessed on: Febr. 3, 2021.).

https://valuetool.pl/en/offer/value-products/ vacuum-pumps/single-stage-vacuum-pumps/vi120sv/product_data_sheet 